\title{
Study of MWCNT / SnO2/Ru thick-film sensors for detecting the presence of certain harmful gases in air
}

\author{
https://doi.org/10.52853/18291171-2021.14.1-49
}

\author{
Z.N. Adamyan*, A.G. Sayunts, E.A. Khachaturyan, V.M. Aroutiounian \\ Department of Physics of Semiconductors and Microelectronics, Center of Semiconductor Devices and \\ Nanotechnologies, Yerevan State University, 1, A. Manoukian, 0025 Yerevan, Armenia, \\ *E-mail:zad@ysu.am
}

Received 18 March 2021

\begin{abstract}
Thick-film VOCs sensors based on ruthenated multi-walled carbon nanotubes coated with tin-dioxide nanoparticles $\left(\mathrm{MWCNTs} / \mathrm{SnO}_{2}\right)$ nanocomposite structures are prepared using three methods: hydrothermal synthesis, sol-gel technique and their combined method. It is shown that the optimal conditions for applications as acetone and toluene as well as ethanol and methanol vapors sensors in view of high response and selectivity relative to each other depend on choice of material synthesis method, mass ratio of the nanocomposite components and selected operating temperature. Selective sensitivity to acetone and toluene vapors at $150^{\circ} \mathrm{C}$ operating temperature MWCNTs/ $\mathrm{SnO}_{2}$ are shown sensor structures with the mass ratio of the components 1:4 and 1:24, respectively. The samples with 1:200 mass ratio of the nanocomposite components are shown the selective response to acetone vapor exposure in the range of $200-250^{\circ} \mathrm{C}$ operating temperatures. The high sensitivity to ethanol and methanol vapors at $200^{\circ} \mathrm{C}$ operating temperature was revealed for the sensor structures made by different methods with the 1:8, 1:24, 1:50 and 1:66 ratios of the components, respectively.

The results of research works related to the study of thick-film multiwall carbon nanotubetin oxide nanocomposite sensors of propylene glycol (PG), dimethylformamide (DMF) and formaldehyde (FA) vapors are also presented in this paper. Investigations of response-recovery characteristics in the $50-300^{\circ} \mathrm{C}$ operating temperature range reveal that the optimal operating temperature for PG, DMF and FA vapor sensors, taking into account both high response and acceptable response and recovery times are about 200 and $220^{\circ} \mathrm{C}$, respectively. The dependence of the sensor response on gas concentration is linear in all cases. Minimal propylene glycol, dimethylformamide and formaldehyde gas concentrations, where the perceptible signal was noticed, were 13, 5 and 115 ppm, respectively.
\end{abstract}

Keywords: MWCNTs/SnO 2 , VOCs, sensor acetone, toluene, propylene glycol, dimethylformamide, formaldehyde

\section{Introduction}

State-of-the-art growing of the sensing technology is generated a need of mankind safety and security as well as monitoring of air pollution. So, air pollution influences human health and can cause a number of diseases. The main air pollutants are some inorganic gases (e.g. $\mathrm{CO}$, $\mathrm{NO}_{x}$, and $\mathrm{SO}_{2}$ ) as well as various volatile organic compounds (VOCs). Toxic and pollutant VOCs such as acetone, toluene, and formaldehyde are found in indoors. The main sources the same VOCs in outdoor are industrial emissions, combustion processes, traffic vehicles and fuel 
evaporation [1]. In indoor environments such as homes, workplaces, cars and shopping centers, these contaminants originate from building materials such as paints, varnish thinners, coatings and furniture [2]. Since, the probability of over exposure to these contaminants now is very high, gas sensing devices installation in such places and develop of advanced monitoring systems for their early detection are necessary.

VOCs detection may also be applied in breathalyzers and medical processes such as disease diagnoses and controlling. Some VOCs such as, acetaldehyde, ethanol, methanol and acetone [3-5] are dangerous else because they do not only pollute the environment but also break down to more toxic substances directly deteriorate human's health depending on such a VOCs used amount [6,7]. So, ethanol used in drink reduces human's consciousness and reaction and becomes a major cause of car accidents. In addition, acetaldehyde is formed in the body as a result of mucosal and microbial oxidation of ethanol [8]. But, it is known that acetaldehyde itself is an irritant of the skin, eyes, mucous membranes, throat, and respiratory tract. This occurs at concentrations up to $1000 \mathrm{ppm}$. Symptoms of exposure to this compound include nausea, vomiting, headache.

Acetone widely used in industries and labs. It is extensively used to dissolve plastic, purify paraffin, and dehydrate tissues in pharmaceutics. Inhalation of acetone causes headache, fatigue and even narcosis and harmfulness to nerve system.

Acetone is other important VOCs in breath. Highly sensitive acetone gas sensors is essential for identification of diabetes and monitoring health conditions and treatment of diabetic patients $[9,10]$. As a case in point, if the maximum acetone concentration in breath more than 1.8 ppm this could indicate high ketone level in blood symptom of insulin-dependent diabetes [3,11].

The rapid and sensitive analysis of acetone gas concentration in human breath is a key technique for noninvasive diagnosis of diabetes. The traditional gas chromatography system as well as calorimetric and optical methods [12,13] or some others [14] used for this purpose is expensive and requires special knowledge for operation [15], which is not suitable for real-time measurements.

Gas sensors based on nanostructured semiconductor metal-oxides materials such as nanoparticles [16-18], nanowires [19-21], nanobelts [22], polycrystalline nanotubes [23], nanorods [24], hollow spheres and nanofibers [25,26], 3D aloe-like [26] and/or their nanocomposites with carbon nanotubes (CNTs) [28-32] are considered as the most promising for applications in gas detection systems and devices. CNTs in it possess by a number of useful behaviors such as a wide range of electrical properties, small size, high structural and chemical stability, high strength and so on. Dew to introduction of CNTs to metal-oxide matrix or deposition of metal-oxide nanoparticles on the nanotubes walls, specific surface area of such gas-sensitive nanocomposites increases still more. Moreover, additional nanochannels in the form of hollow CNTs for gas diffusion appear [33-35]. Hence, it can be expected that application of nanocomposite hybrid structures composed of functionalized CNTs and metal oxide in gas sensors technology should improve the gas sensor parameters, particularly, gas sensitivity, response and recovery times as well as reduce the operating temperatures.

As a gas-sensitive materials meant for use in high performance gas sensor applications both taken separately and as a component of hybrid system, researches have mainly focused their efforts on n-type nanostructured metal-oxides such as $\mathrm{SnO}_{2}, \mathrm{In}_{2} \mathrm{O}_{3}, \mathrm{ZnO}, \mathrm{WO}_{3}, \mathrm{TiO}_{2}$ and their 
compounds [3-7,9,11,15-18]. Among them, $\mathrm{SnO}_{2}$ is the most prospective and widely used gassensitive material for the gas sensor to detect a wide variety of pollutant gases dew to its attractive features including high gas sensitivity, relatively low specific resistance and operating temperatures, chemical durability, low cost, nontoxicity, and simple preparation [36].

In previous works $[31,32]$, we had shown that the functionalization of multi-walled carbon nanotube (MWCNT) $/ \mathrm{SnO}_{2}$ thick-film structures by $\mathrm{Ru}$ leads to considerable increase in response signal to methanol and ethanol vapors as well as to i-butane gas. However, the selectivity problem of studied sensors relative to other gases, particularly to some harmful and toxic VOCs exposure remained not solved. The goal of present work is bring to light on optimal conditions at which the best level of the selectivity these sensors to various VOCs achieves.

There are various harmful and hazardous matter vapors, which have a major role in diverse spheres such as environmental protection, industrial manufacturing, medicine and national defense. As an illustration, propylene glycol is an excellent solvent for many organic compounds and is used as an active ingredient in engine coolants and antifreeze, brakes, paints, enamels and varnishes, and also as a solvent or surfactant in many products. It also can be found in cosmetics, perfumes and pharmaceuticals. Another example is dimethylformamide (DMF) which is used as a solvent in vinyl resins, adhesives, pesticide and epoxy formulations. It purifies and separates acetylene, 1,3-butadiene, acid gases and aliphatic hydrocarbons. DMF is also used in the production of polyacrylic or cellulose triacetate fibers and pharmaceuticals or in the production of polyurethane resin for synthetic leather [37].

Formaldehyde (FA) is a colorless, water-soluble gas with a pungent odor, which used in making building materials and in many household products such as particleboard, plywood and fiberboard, glues and adhesives, textiles, papers and their product coatings. Besides, formaldehyde can serve an intermediate product in the manufacture of industrial chemicals. It can also be found as a preservative substance in some foods and products, such as antiseptics, medicines and cosmetics [38].

DMF, PG and FA have a huge impact on human organs (e.g. liver, skin, eyes and kidneys) [37-40]. PG can cause nausea and vomiting, headaches, dizziness and fainting. Moreover, it is known as a combustible liquid, which can explode in fire. A minimal risk level of $0.009 \mathrm{ppm}$ has been derived for constant-duration (15-364 days) inhalation exposure to propylene glycol [41]. FA gas can cause burning sensations in the eyes, nose and throat as well as cause coughing, wheezing, nausea and skin irritation. Besides, exposure to relatively high amounts of formaldehyde can increase the risk of leukemia and even cause some types of cancer in humans.

The United States Occupational Safety and Health Administration (OSHA) have set its short-term exposure limit (15-30 min) at 2 ppm and permissible exposure limit (up to $8 \mathrm{~h}$ ) to $0.75 \mathrm{ppm}$ [42]. The current OSHA standard for dimethylformamide is $10 \mathrm{ppm}$ averaged over an $8 h$ work shift [43].

Due to the information noted above, PG, DMF and FA gas sensors are commonly applied for detecting and continuously monitoring these gases in the spheres where they are used.

In this paper, we report the some VOCs sensing properties of various ruthenated MWCNT $/ \mathrm{SnO}_{2}$ nanocomposite structures as thick films obtained by hydrothermal synthesis and sol-gel techniques as well as theirs combination. The choice of corresponding treating conditions and 
regimes for CNTs functionalization as well as thick films surface modification with Ru catalyst were focused on obtaining sensitivity to such target gases as ethanol, methanol, acetone, toluene, propylene glycol, dimethylformamide and formaldehyde.

\section{Experimental}

\subsection{Materials preparation}

MWCNTs $/ \mathrm{SnO}_{2}$ nanopowders for thick film preparation were made by the following three ways: using sol-gel preparation technique, hydrothermal synthesis and their two-step combination.

To making the nanocomposite structures according to the first way, MWCNTs membranes were used for preparation of nanocrystalline MWCNTs $/ \mathrm{SnO}_{2}$ powder. MWCNTs were prepared by the decomposition of acetylene (CVD method) using $\mathrm{Fe}, \mathrm{Co} / \mathrm{CaCO}_{3}$ catalyst [44, 45]. This growth procedure using $\mathrm{CaCO}_{3}$ catalyst enables a highly efficient selective formation of clean MWCNTs, suitable for effective bonding between CNT and metal-oxide, particularly, $\mathrm{SnO}_{2}$ precursors.

For a functionalization of nanotube walls with oxygen-containing hydroxyl $(\mathrm{OH})$, carbonyl $(\mathrm{C}=\mathrm{O})$, and carboxylic $(\mathrm{COOH})$ functional groups, MWCNTs from the membranes were transferred to slurry in $\mathrm{HNO}_{3} / \mathrm{H}_{2} \mathrm{SO}_{4}$ acids mixture during $1 \mathrm{~h}$. Such a functionalization of the CNTs is very important and necessary for the following synthesis of $\mathrm{SnO}_{2}$ nanoparticles on the MWCNTs walls since these oxygen-containing groups act as sites for nucleation of nanoparticles. After rinsing by distilled water and drying at $80^{\circ} \mathrm{C}$ MWCNTs were poured and treated in deionized water in ultrasonic bath for $5 \mathrm{~min}$.

In the next step, the purified MWCNT and the calculated water solution of the $\mathrm{SnCl}_{4} \cdot 5 \mathrm{H}_{2} \mathrm{O}$ precursor were mixed for a further $5 \mathrm{~h}$ at $140^{\circ} \mathrm{C}$. After that, precipitate was collected for the following synthesis of hybrid material. For that, the precursor solution was added to all of the precipitate. Obtained mixture was exposed to ultrasonic treatment for $5 \mathrm{~min}$. The mixed suspension was left overnight at $80^{\circ} \mathrm{C}$, whereupon MWCNTs $/ \mathrm{SnO}_{2}$ composite powder with $0.1 \%$ addition of the MWCNTs was rinsed, dried, grinded and annealed in air at $400^{\circ} \mathrm{C}$ for $1 \mathrm{~h}$. The final mass ratio of MWCNTs $/ \mathrm{SnO}_{2}$ composite was 1:50, respectively. This sol-gel process is presented elsewhere [31], in detail.

The preparation of $\mathrm{SnO}_{2}$ / MWCNT nanocomposite materials with a hydrothermal method was carried out in two steps. The preparation of nanocomposite materials with a hydrothermal method was carried out in two steps. At first, purified MWCNTs was well dispersed in water via sonication. After that, a calculated amount of the $\mathrm{SnCl}_{2} \cdot 2 \mathrm{H}_{2} \mathrm{O}$ precursor was dissolved in another beaker in water, whereupon $3 \mathrm{~cm}^{3} \mathrm{HCl}$ was added to the solution. In the next step, the MWCNT suspension and the solution of the precursor were mixed and sonicated for $30 \mathrm{~min}$. In 
order to prepare the nanocomposites we poured the above-mentioned solutions into autoclaves where hydrothermal synthesis was carried out at $150^{\circ} \mathrm{C}$ for 1 day. At the end of this procedure, all obtained nanocomposite powders were filtered and then dried at $90^{\circ} \mathrm{C}$ for $5 h$. The final mass ratios of the MWCNT $/ \mathrm{SnO}_{2}$ nanocomposite obtained with a hydrothermal method were $1: 4,1: 8,1: 66$, and $1: 200$, respectively.

The third type of composite material using both hydrothermal and wet chemical methods was obtained by following route. Firstly, we were prepared $45 \mathrm{ml} \quad 0.5 \mathrm{M} \quad \mathrm{SnCl}_{4} \quad 5 \mathrm{H}_{2} \mathrm{O}$ deionized water solution. Then, $11 \mathrm{mg}$ obtained $\mathrm{MWCNT} / \mathrm{SnO}_{2}$ powder synthesized by above-mentioned hydrothermal method was added to the solution with thorough mixing by magnetic stirrer. Simultaneously, ammonium was added drop by drop to the solution at $42^{\circ} \mathrm{C}$ on reaching $p H=9$. After that, the solution was left in the thermostat at $80^{\circ} \mathrm{C}$ for 24 hour. Resulting slurry with deionized water addition was centrifuged at a spinning rate of $7000 \mathrm{rpm}$ with further washing of the precipitates. Spinning and washing processes were carried out as long as chlorides in the solution disappear entirely. Then, the purified from chlorides sediment was left at $140^{\circ} \mathrm{C}$ overnight. Obtained powder was annealed in air at $400^{\circ} \mathrm{C}$ for 3 hours. The final mass ratio of obtained by such a way MWCNTs $/ \mathrm{SnO}_{2}$ composite components was 1:24, respectively.

The chose water as a solvent, instead of e.g. ethanol, in all presented here three material preparation methods was preferably for us in the view of expected improvement in gas sensing characteristics, taking in account the fact that cover the overwhelming parts of CNTs with $\mathrm{SnO}_{2}$ nanoparticles is ensured at that [46].

\subsection{Samples}

The thick films were obtained on the base of all MWCNTs $/ \mathrm{SnO}_{2}$ composite powders. The paste for thick film deposition made by mixing powders with $\alpha$-terpineol ("Sigma Aldrich") and methanol was printed on chemically treated surface of the alumina substrate over the ready-made Pt interdigitated electrodes. The thin-film $P t$ heater was formed on the back side of the substrate. Obtained composite structures were cut into $3 \times 3 \mathrm{~mm}$ pieces. Drying and annealing of the resulting thick films were carried out in two stages: heating up to $220^{\circ} \mathrm{C}$ with $2^{0} \mathrm{C} \mathrm{min}^{-1}$ rate of temperature rise, hold this temperature for $3 h$ and then further temperature increase until $400^{0} \mathrm{C}$ with $1^{0} \mathrm{C} \mathrm{min}^{-1}$ rate and hold again for $3 h$. Then, the thick-film specimens were cooled down in common with the oven.

After annealing and cooling processes, the MWCNTs $/ \mathrm{SnO}_{2}$ thick films were surfaceruthenated by dipping them into the $0.01 \mathrm{M} \mathrm{RuOHCl}$ aqueous solution for $20 \mathrm{~min}$ whereupon dried at $80^{\circ} \mathrm{C}$ for $30 \mathrm{~min}$ and then annealing treatment was carried out again at the same abovementioned mode. The choice of the ruthenium as a catalyst was defined by its some advantages [31]. Further, ruthenated MWCNT/SnO 2 chips were arranged in TO-5 packages and after leads bonding offered gas sensors were ready to measurements. 


\subsection{Gas sensing measurements}

VOCs vapors sensing properties of the MWCNTs $/ \mathrm{SnO}_{2}$ composite structures were measured by home-made developed computer-controlled static gas sensor test system [40]. The sensors were re-heated at different operating temperatures. When the resistances of all the sensors were stable, saturated target vapor was injected into a measurement chamber by a microsyringe. The target gases including acetone, toluene, ethanol, methanol vapors were introduced in the measurement chamber on special hot plate designed for the quickly conversion of the liquid substance to its gas phase $(\leq 12 s)$. After the sensor resistances reached a new constant value, the test chamber was opened to recover the sensors in air. The sensing characteristics were studied at a temperature range of $100-300^{\circ} C$. The gas response $S$ of the sensors was defined as $R_{a} / R_{g}$ where $R_{a}$ and $R_{g}$ are the electrical resistances in air and in target VOCs-air mixed gas, respectively. The response and recovery times are defined as the time required for reaching $90 \%$ resistance change from the corresponding steady-state value of the signal.

The volume part of the gas in air was calculated by the following equation:

$$
C_{p p m}=\frac{\rho \times V_{l} \times R \times T}{M \times P_{v} \times V_{c h}} \times 10^{6}
$$

where $\rho\left(\mathrm{g} / \mathrm{cm}^{3}\right)$ is the density of injected liquid, $V_{l}$ is the volume of the injected liquid, $R$ is the universal gas constant, $T$ is the absolute temperature, $M(\mathrm{~g} / \mathrm{mol})$ is the molecular weight, $P_{v}$ is the pressure after the vaporization of the injected liquid, $V_{c h}$ is the volume of the chamber.

\section{Results and discussions}

\subsection{Material characterization}

The morphologies of the prepared $\mathrm{SnO}_{2} / \mathrm{MWCNT}$ nanocomposite different powders were studied by scanning electron microscopy (SEM) using Hitachi S-4700 Type II FE-SEM equipped with a cold field emission gun operating in the range of $5-15 k \mathrm{~V}$. The samples were mounted on a conductive carbon tape and sputtered with a thin $A u / P d$ layer in $A r$ atmosphere prior to the measurement.

Fig. 1 shows SEM image of the pristine carbon nanotubes lying in the MWCNTs membrane. The rough estimation of the CNTs sizes shows that the average diameter of carbon nanotubes not covered with $\mathrm{SnO}_{2}$ nanoparticles clusters is about $25 \mathrm{~nm}$.

In previous published results [31], we were shown that with increasing the weight ratio of the MWCNT $/ \mathrm{SnO}_{2}$ nanocomposite components from 1:4 to 1:50 the inorganic coverage of carbon nanotubes becomes thicker and thicker. Comparison of these results with ones obtained for the samples with the weight ratios 1:66 and 1:200 were verified this tendency. 
The micrograph for specimen with the $1: 4$ weight the ratio of the components presented in Fig. 2 shows that spherical tin oxide nanoparticles covered the CNTs are well dispersed and separated from each other whereas in the case of the 1:66 one (see Fig. 3) $\mathrm{SnO}_{2}$ nanoparticles are conjugated into the clusters. .

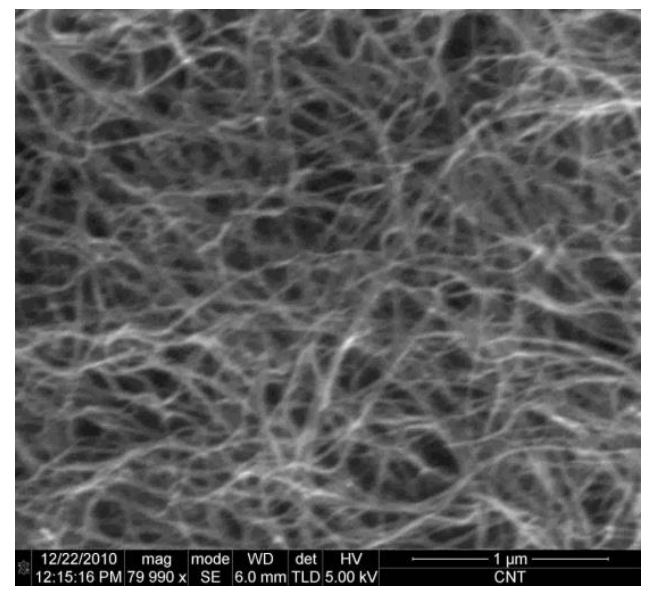

Fig. 1. SEM image of the pristine CNTs.

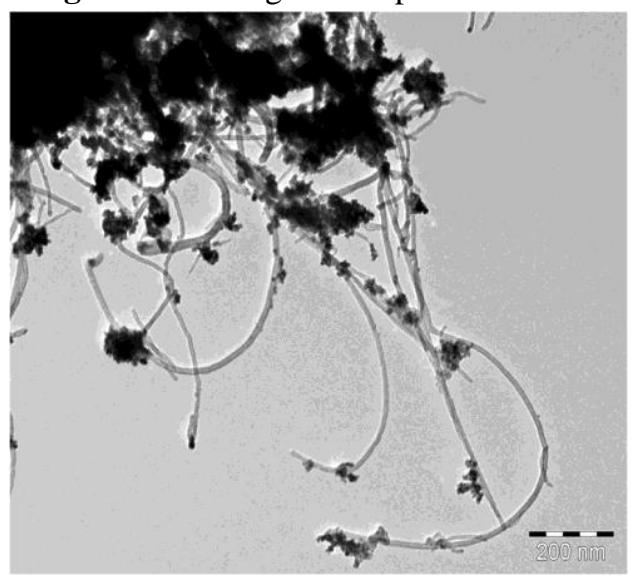

Fig.2. TEM image of MWCNT/SnO ${ }_{2}$ nanocomposite with the 1:4 ratios of the components.

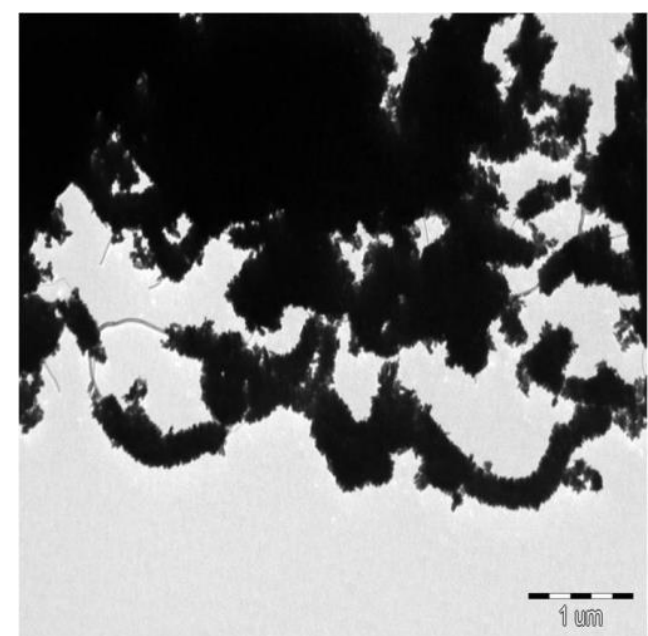

Fig.3. TEM image of MWCNT/SnO 2 nanocomposite with the 1:66 ratios of the components. 
The presence of an oxide layer was confirmed by SEM-EDX and the crystalline structure of the inorganic layer was also studied by an $X$ - ray diffraction method using Rigaku Miniflex II diffractometer (angle range: $2 \theta\left[{ }^{0}\right]=10-80$ utilizing characteristic $X$ - ray $(C u \mathrm{~K} \alpha)$ radiation). Results of these studies are presented in [31] in detail. Here, we are only noted that average crystalline size of $\mathrm{SnO}_{2}$ nanoparticles are less than $12 \mathrm{~nm}$ for all using synthesis methods but the average diameter of non-covered $\mathrm{SnO}_{2}$ nanoparticles CNTs was about $40 \mathrm{~nm}$.

\subsection{Gas sensing characteristics}

\subsubsection{Acetone and Toluene vapor sensing characteristics}

At first, we consider the response from presence of methanol and ethanol vapors in the measurement chamber atmosphere. As a result of our studies, we were revealed that the most response from these alcohols inherent to sets of $\mathrm{MWCNT} / \mathrm{SnO} \mathrm{O}_{2}$ nanocomposite samples made by all mentioned above material synthesis methods with corresponding ratios of the components beginning from $1: 8$ up to $1: 200$, at $200^{\circ} C$ operating temperature. Results of these measurements and samples codes with corresponding synthesis methods are summarized in Table 1 and bar chart (Fig.4) below.

Table 1. The response of studied $\mathrm{MWCNT} / \mathrm{SnO}_{2}$ nanocomposite samples to 1000 ppm of different gases at $200^{\circ} \mathrm{C}$ operating temperature.

\begin{tabular}{|c|c|c|c|}
\hline $\begin{array}{c}\text { Sample } \\
\text { code }\end{array}$ & $\begin{array}{c}\text { Process } \\
\text { parameters }\end{array}$ & $\mathrm{R}_{\text {air }} / \mathrm{R}_{\text {methanol }}$ & $\mathrm{R}_{\text {air }} / \mathrm{R}_{\text {ethanol }}$ \\
\hline KCS1-3 & $\begin{array}{c}\text { Hydrothermal } \\
\text { synthesis, 1:4 }\end{array}$ & 22 & 14 \\
\hline KCS2-2 & $\begin{array}{c}\text { Hydrothermal } \\
\text { synthesis, 1:8 }\end{array}$ & 1500 & 500 \\
\hline EKCS3-2 & $\begin{array}{c}\text { Hybrid method, } \\
1: 24\end{array}$ & 1000 & 750 \\
\hline ECS7-2 & $\begin{array}{c}\text { Sol-gel, 1:50 } \\
\text { ZCS-66 }\end{array}$ & $\begin{array}{c}\text { Hydrothermal } \\
\text { synthesis, 1:66 }\end{array}$ & 7000 \\
\hline ZCS-200 & $\begin{array}{c}\text { Hydrothermal } \\
\text { synthesis, 1:200 }\end{array}$ & 384 & 600 \\
\hline
\end{tabular}




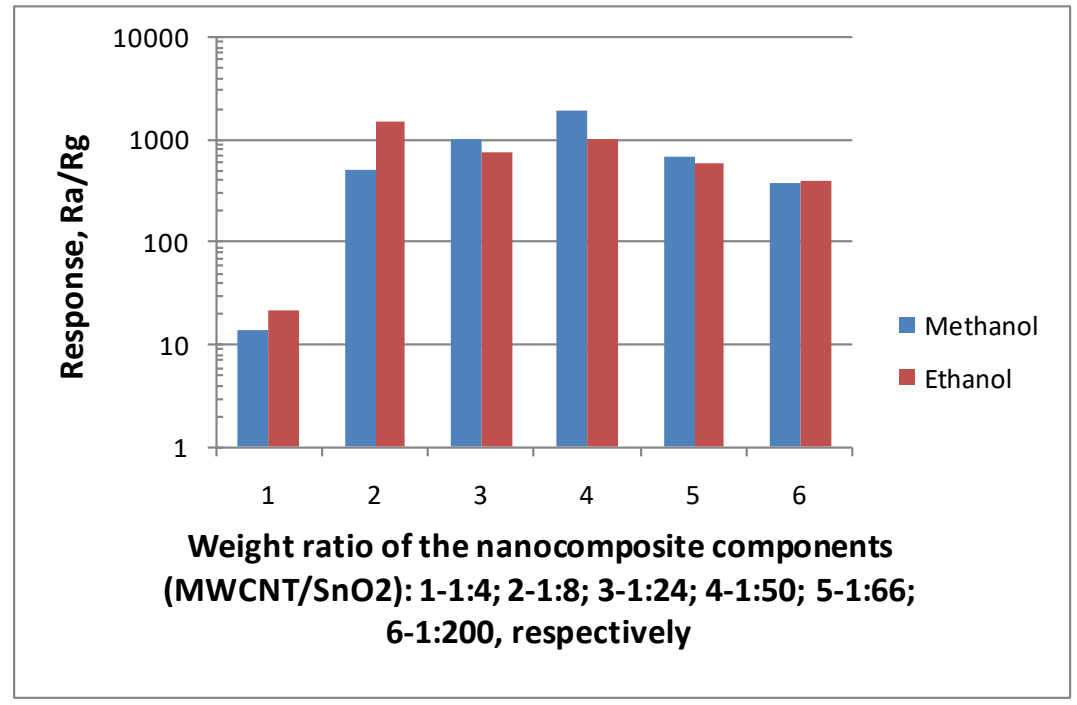

Fig.4. Response to $1000 \mathrm{ppm}$ methanol and ethanol at $200^{\circ} \mathrm{C}$ operating temperature for studied VOCs sensors.

It can be seen from diagram, beginning from 1:8 weight ratios of the nanocomposite components up to one 1:50, sensors response to methanol and ethanol vapors not vary practically. Moreover, we can assert that in this range of weight ratio of the nanocomposite components, the sensors made by using the mentioned above different three technologies react to these alcohols something like. But, further increase in $\mathrm{SnO}_{2}$ component of the nanocomposite result in gradual decrease in ethanol and methanol vapors responses. Nevertheless, sensitivity to these alcohols vapors remains as long as high. As distinct from previous study [31], here we consider the more range of weight ratio of the nanocomposite components as well as addition of new hybrid nanocomposite synthesis method. From this it follows that sensitivity of studied sensors for methanol and ethanol vapors not so much depends from material synthesis methods as rather than sensors operating temperature and required definite amount of $\mathrm{SnO}_{2}$ nanoparticles covered with MWCNTs walls.

It should be noted that $200^{\circ} \mathrm{C}$ is optimal operating temperature for detection of methanol and ethanol vapors by such nanocomposite sensors. But, we were set ourselves as an object to find conditions and corresponding material technology at which the best selectivity to one or another gases achieves. With this purpose, we were carried out the testing of all samples at different operating temperatures in other to compare responses to various considered here target VOCs. Results of these investigations fulfilled for set of ECS7-2 series samples summarized in Fig. 5. The relatively high $1000 \mathrm{ppm}$ concentration is chosen for selectivity better shows. 


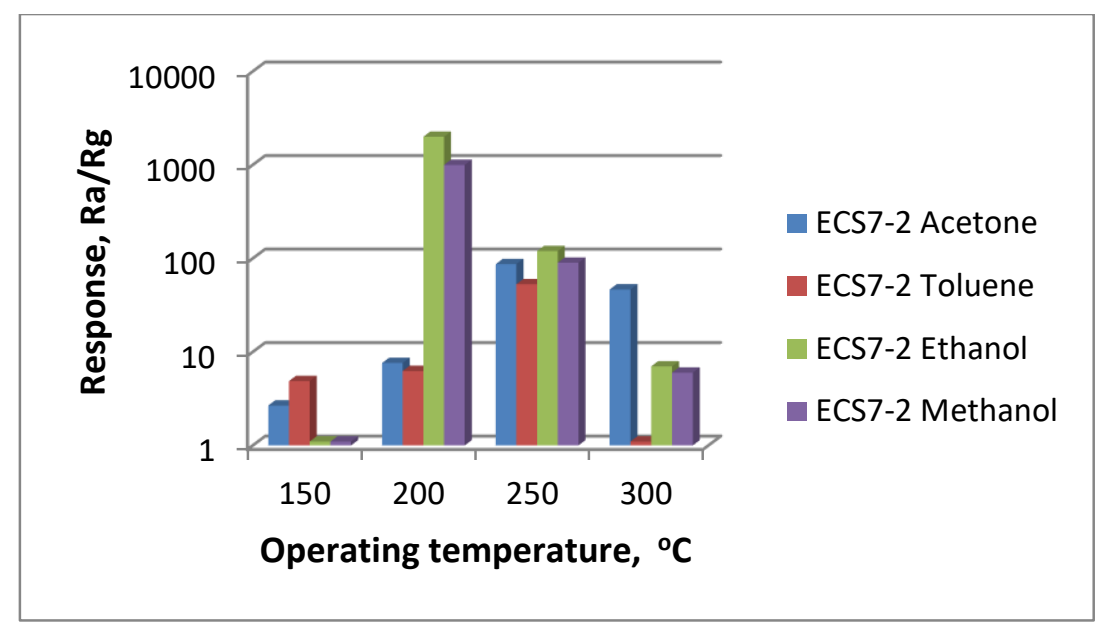

Fig. 5. Comparison of ECS7-2 series sample responses to $1000 \mathrm{ppm}$ different VOC exposure vs operating temperature.

It is obvious that the best selectivity relative to other VOC and high response values are registered at methanol and ethanol vapors exposure at $200^{\circ} C$ operating temperature. Unfortunately, separate detection of methanol and ethanol vapors is not come in as yet. There is not selectivity at $250^{\circ} \mathrm{C}$ operating temperature though at that relatively high response observed for all target VOCs. While, the same series samples are shown the sufficiently selective detection of acetone vapors at $300^{\circ} \mathrm{C}$.

Taking into account the fact that KCS1-3 set of samples with 1:4 ratio of the nanocomposite components also selectively sensitive to the alcohols only at $200^{\circ} \mathrm{C}$ but with lesser responses, we were hoped obtaining selective sensitivity to acetone or toluene vapors at lower or higher operating temperatures. The responses of KCS1-3 samples to studied VOCs vs operating temperature is presented in Fig.6. It can be seen that the selective sensitivity these samples to acetone vapors at the same concentration of all vapors is observed as early as at $150^{\circ} \mathrm{C}$ operating temperature. With increase in operating temperature, the response to acetone vapor rises up to 360.4 value at $250^{\circ} \mathrm{C}$ while selectivity remains high. Undoubtedly, functioning at lower operating temperature $\left(150^{\circ} \mathrm{C}\right)$ with ensuring the best selectivity is preferably in all cases. 


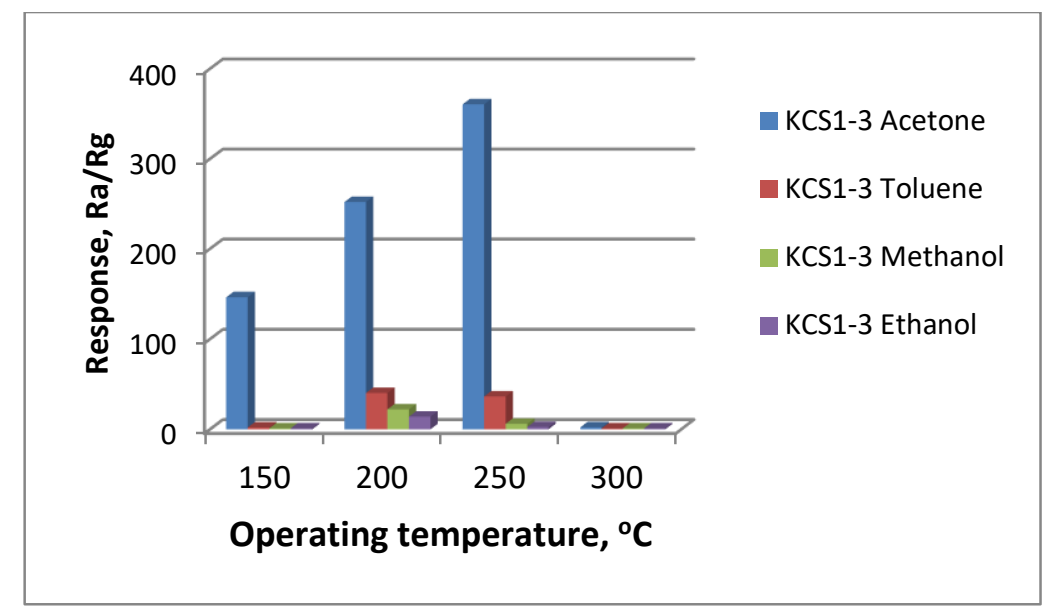

Fig. 6. The responses of specimens on KCS1-3 set of samples to studied VOCs exposure vs operating temperature.

As for EKCS3-2 set of samples made by applying of the hybrid technology, we should be noted that the high response to acetone and toluene vapors of these sensors appears at $200^{\circ} \mathrm{C}$ but selectivity at that is poor. The selective response to toluene vapors is observed at $150^{\circ} \mathrm{C}$ (Fig.7). Thus, KCS1-3 and EKCS3-2 series samples functioned at relatively low operating temperature $\left(150^{\circ} \mathrm{C}\right)$ could be use as toluene and acetone vapors sensors, respectively.

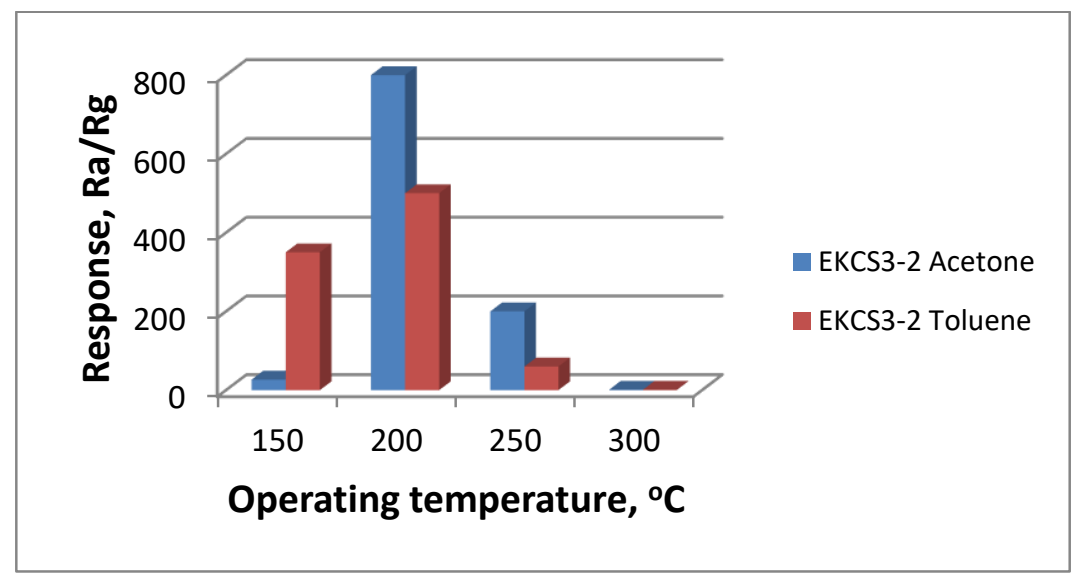

Fig. 7. Response of EKCS3-2 set of samples to the same concentration (500 ppm) of acetone and toluene vapors vs operating temperature.

Sufficiently selective response to acetone vapors is registered by ZCS1-200 set of samples at all operating temperatures in the range of $150-300^{\circ} \mathrm{C}$. Results of the test measurements are shown in Fig. 8. 


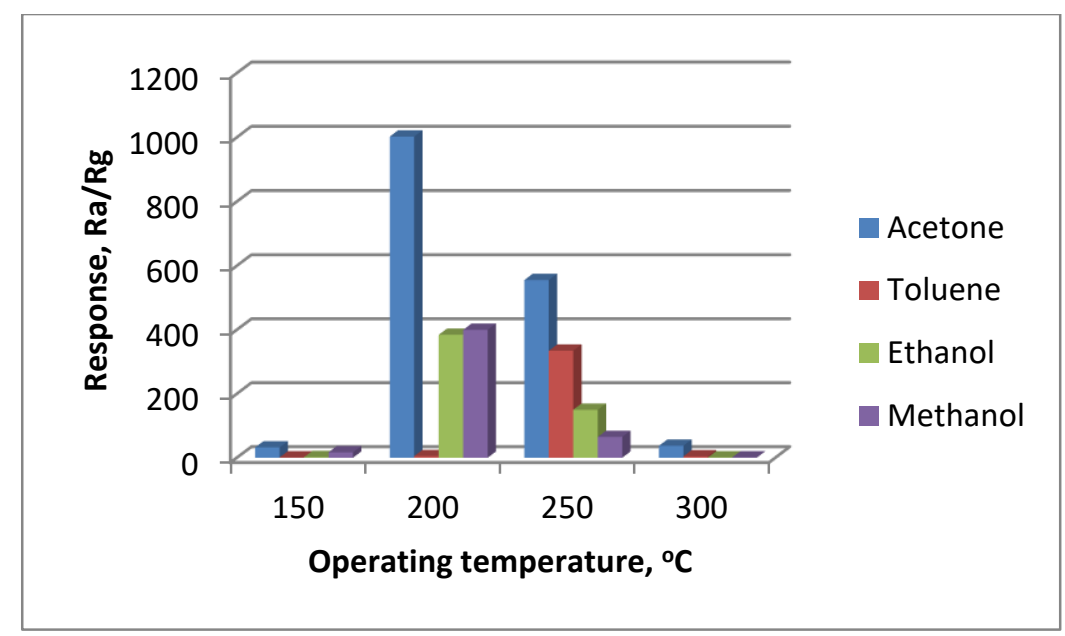

Fig. 8. The responses of specimens on ZCS1-200 set of samples to studied VOCs exposure vs operating temperature.

Data of acetone and toluene responses of considered samples at different operating temperatures are summarized in Table 2.

Table 2. Acetone and toluene vapors responses of all studied samples vs operating temperature.

\begin{tabular}{|c|c|c|c|c|c|c|c|c|}
\hline \multirow{2}{*}{$\begin{array}{c}\text { Operating } \\
\text { temperature, }\end{array}$} & \multicolumn{9}{|c|}{ Gas response, $\mathrm{R}_{\mathrm{a}} / \mathrm{R}_{\mathrm{g}}$} \\
\cline { 2 - 9 }${ }^{\circ} \mathrm{C}$ & \multicolumn{2}{|c|}{ ECS7-2 } & \multicolumn{2}{c|}{ KCS1-3 } & \multicolumn{2}{c|}{ EKCS3-2 } & \multicolumn{2}{c|}{ ZCS1-200 } \\
\cline { 2 - 9 } & Acetone & Toluene & Acetone & Toluene & Acetone & Toluene & Acetone & Toluene \\
\hline 150 & 2.67 & 4.88 & 146.3 & 2 & 26.59 & 350 & 32.3 & 1 \\
\hline 200 & 7.62 & 6.25 & 251.9 & 40.21 & 800 & 500 & 1002.34 & 5 \\
\hline 250 & 86.93 & 52.96 & 360.4 & 84.198 & 200 & 60 & 555.6 & 334.6 \\
\hline 300 & 46.5 & 1 & 2.21 & 1 & 1 & 1 & 37.5 & 4.34 \\
\hline
\end{tabular}

Response and recovery times are defined from transient response-recovery curves and corresponding dynamic resistance change. As examples, here we adduce some of them for different mentioned above gas sensors. These times to differ for studied sensors. For example, the reaction of EKCS3-2 sensors to acetone vapors is rather slow. The recovery at $200^{\circ} \mathrm{C}$ takes place incompletely. Using pulse supply mode for heater full recovery is reached. But, response and recovery times of $\mathrm{KCS} 1-3$ type sensors at $250^{\circ} \mathrm{C}$ operating temperature and $1000 \mathrm{ppm}$ toluene exposure are about only $24 s$ and $14 s$, respectively (Fig. 9). 


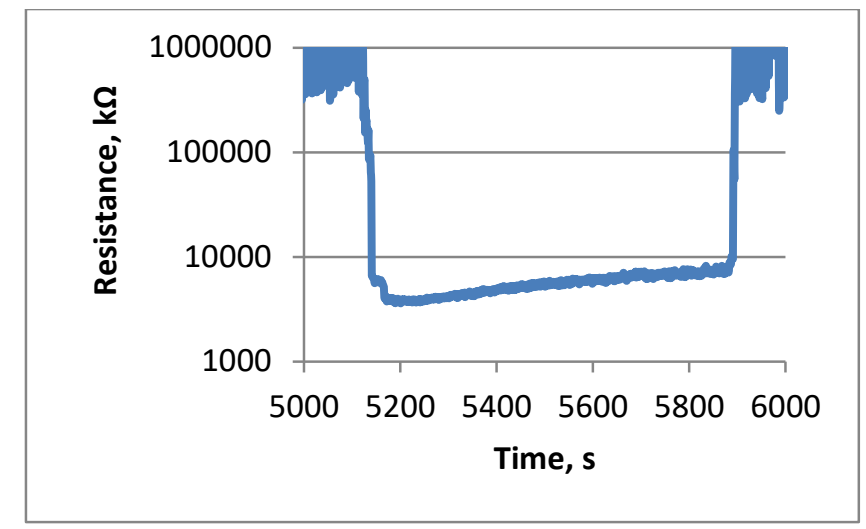

Fig. 9. The response and recovery of KCS1-3 set of samples to $1000 \mathrm{ppm}$ toluene vapors exposure at $250^{\circ} \mathrm{C}$ operating temperature.

The largest response to acetone vapors $\left(R_{a} / R_{g}=555.62\right)$ in steady-state regime (formed after the first acetone vapor influence) is fixed for ZCS1-200 set of samples with 1:200 mass ratio of the components to $1000 \mathrm{ppm}$ acetone vapors exposure at $250^{\circ} \mathrm{C}$ operating temperature (Fig. 10). Response and recovery times of these sensors are about 22 and $27 s$, respectively.

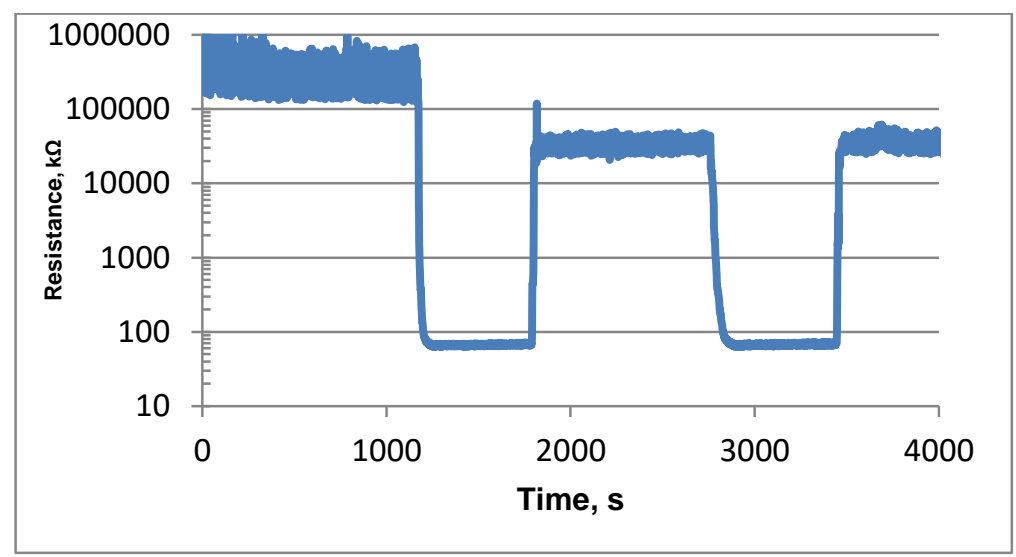

Fig. 10. The response and recovery of ZCS1-200 set of samples with 1:200 mass ratio of the components to $1000 \mathrm{ppm}$ acetone vapors exposure at $250^{\circ} \mathrm{C}$ operating temperature.

As an example, dependence of ZCS1-200 sensor response vs acetone vapor concentration at $150^{\circ} \mathrm{C}$ is presented in Fig. 11. Obviously that gas response linearly increases with acetone vapor concentration build up. 


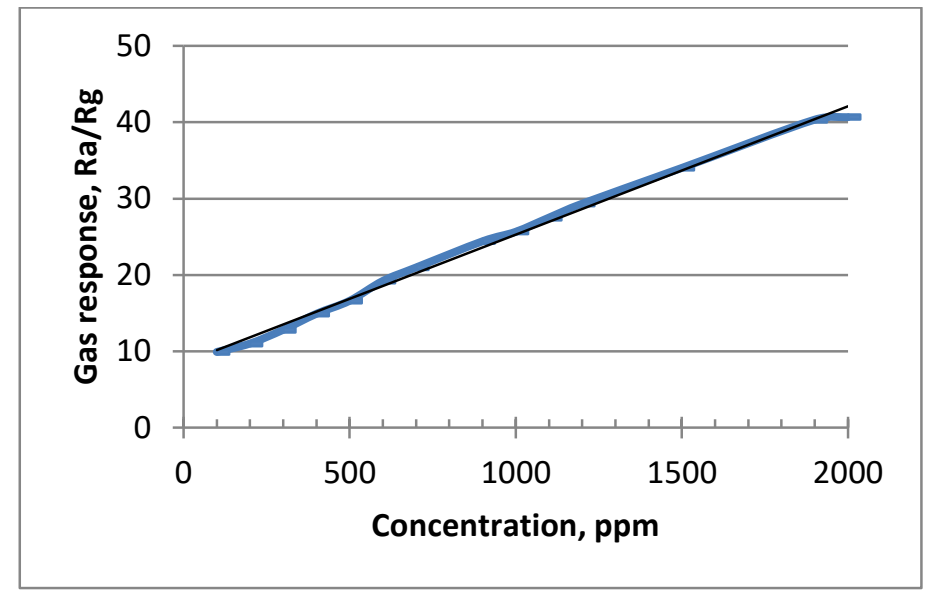

Fig. 12. Dependence of EKCS3-2 sensor response vs acetone vapor concentration.

\subsection{2. $P G, D M F$ and $F A$ vapor sensors characteristics}

As a result of measurements of all the presented above types of sensors in sensitivity to PG, DMF, and FA gases, it was revealed that the best characteristics are inherent in samples with 1:200 ratio of MWCNTs $/ \mathrm{SnO}_{2}$ nanocomposite components, respectively. Therefore, all data presented below are concerned to those sensors

As a result of measurements of the sensor resistance in air and an air-gas environment, the maximal response to $650 \mathrm{ppm}$ PG vapor was revealed at $200^{\circ} \mathrm{C}$ operating temperature (Fig. 12). Dependence of the response of the sensor on operating temperature in the presence of $500 \mathrm{ppm}$ DMF and 1160 ppm FA vapors in the air are also presented in Fig. 12. As demonstrated, the maximal response to FA and DMF vapors are revealed to be in the range of $200-225^{\circ} C$ operating temperatures.

Changes in the resistance of the structure depending on PG and FA gas concentrations are presented in Figs. 12 and 13, respectively. Dependence of the response of MWCNTs / SnO sensors on PG, DMF and FA vapor concentration are shown in Figs. 14 and 15, respectively. As it is obvious from the figures, the sensor response occurs down to small target gas concentrations (13 ppm of PG and 5 ppm of DMF) and the response depends approximately linearly (on a double logarithmic scale in Fig. 14 and in a half logarithmic scale in Fig. 15) on the gas concentration in all cases.- 
Tin Oxide/ Carbon Nanotube Nanocomposite Sensors || Armenian Journal of Physics, 2021, vol. 14, issue 1

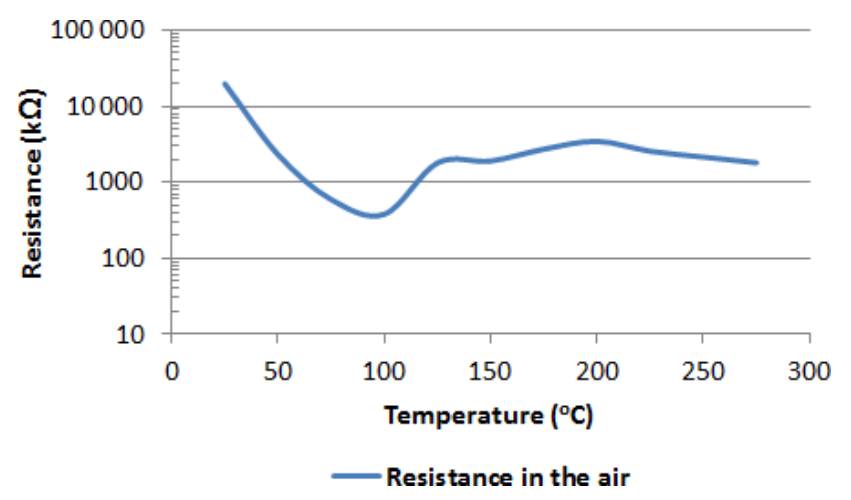

Fig.12. Dependence of $\mathrm{MWCNTs} / \mathrm{SnO}_{2}$ sensors electrical resistance change on operating temperature in the air.

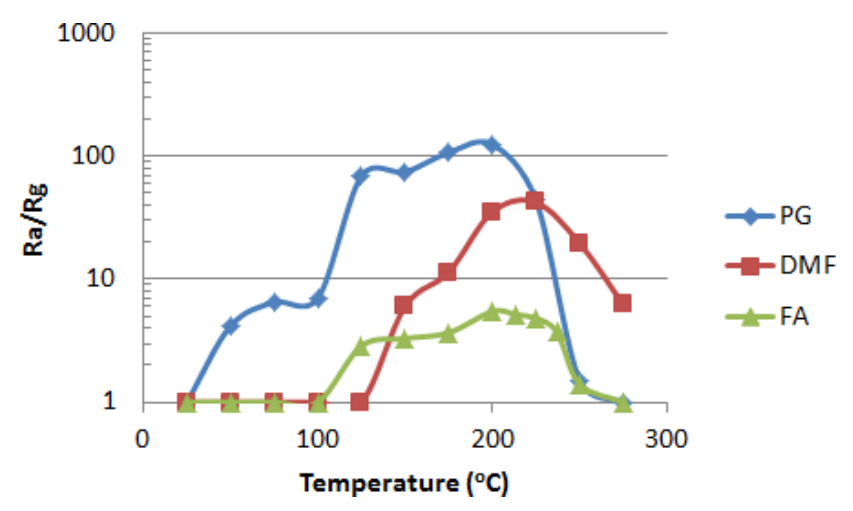

Fig. 13. Response vs. operating temperature at 650 ppm PG, 500 ppm DMF and 1160 ppm FA vapor exposure.

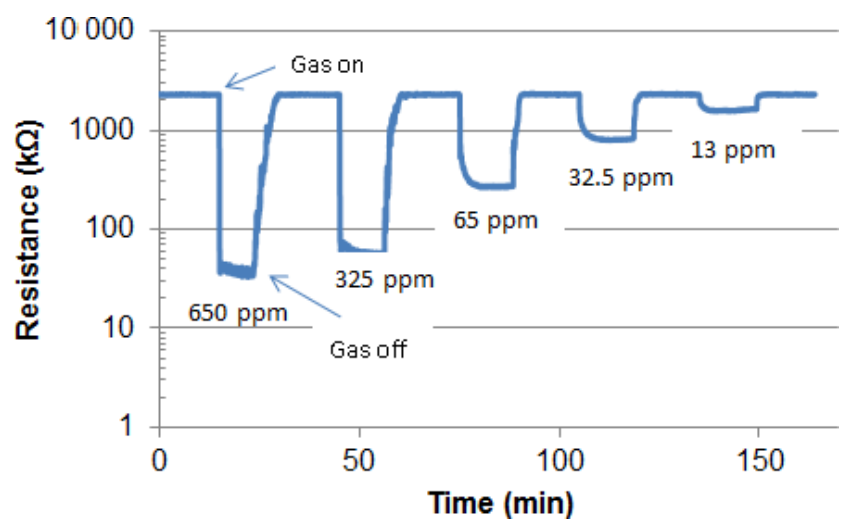

Fig 14. The response-recovery curves observed at different $P G$ concentrations measured at $200{ }^{\circ} \mathrm{C}$ operating temperature. 


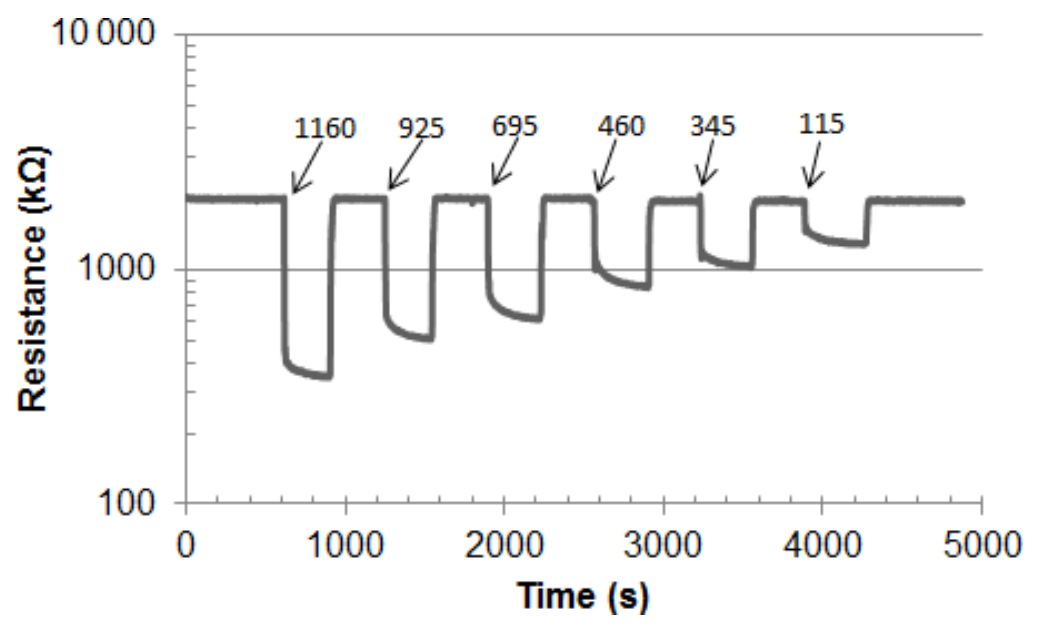

Fig. 15. The response-recovery curves observed at different FA vapor concentrations (values in ppm indicated by the numbers above the arrows) measured at $200{ }^{\circ} \mathrm{C}$ operating temperature.

Good repeatability of the sensor response can be seen from Fig. 16, where the electrical resistance change in PG sensor vs. time measured upon cyclic exposure of 650 ppm PG vapors in air at $200^{\circ} \mathrm{C}$ operating temperature is presented.

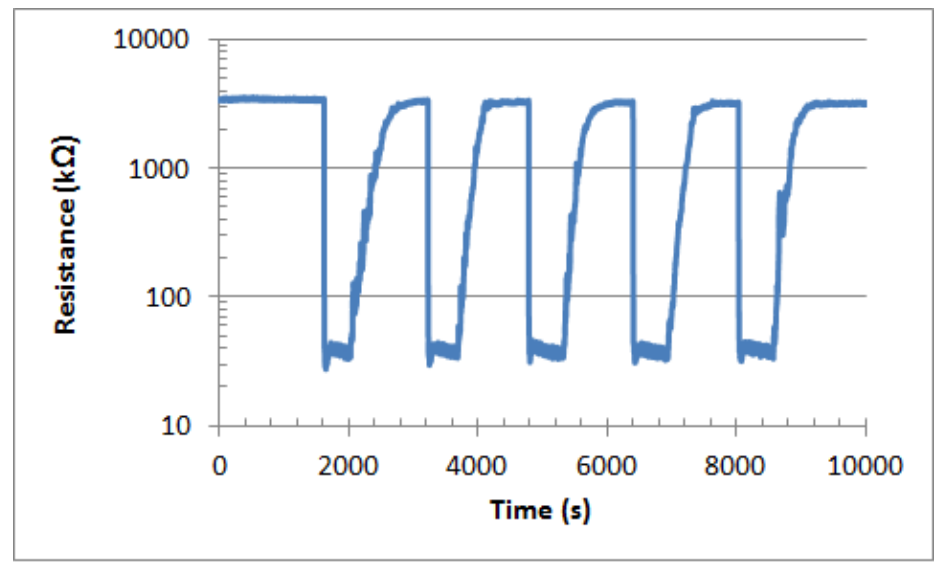

Fig. 16. The electrical resistance change in $\mathrm{MWCNTs} / \mathrm{SnO}_{2}$ thick-film $\mathrm{PG}$ sensors vs. time measured upon cyclic exposure of $650 \mathrm{ppm} \mathrm{PG}$ vapors in air at $200^{\circ} \mathrm{C}$ operating temperature.

Changes in the response and recovery times of the sensors depending on PG, DMF and FA vapor concentration are presented in Figs. 17, 18 and 19, respectively. 
Tin Oxide/ Carbon Nanotube Nanocomposite Sensors || Armenian Journal of Physics, 2021, vol. 14, issue 1

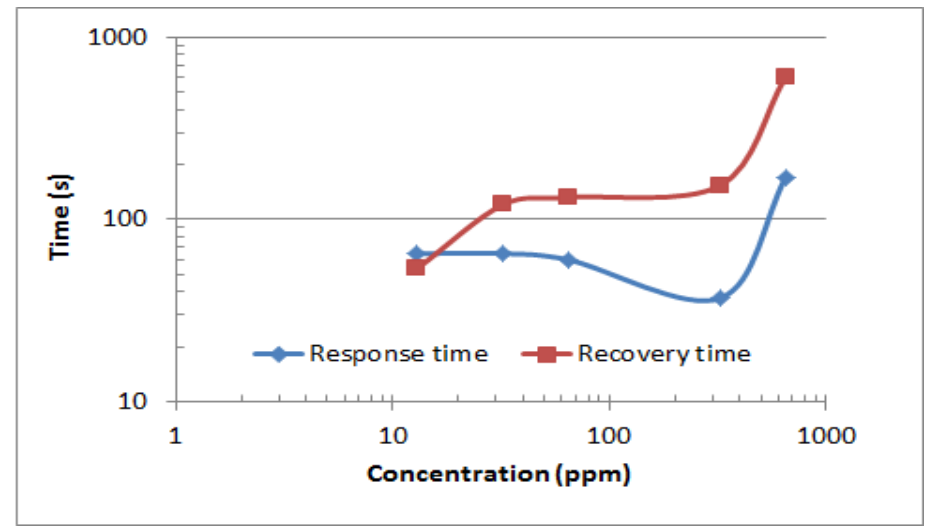

Fig. 17. Dependence of response and recovery times of $\mathrm{MWCNTs} / \mathrm{SnO}_{2} \mathrm{PG}$ vapor sensor on gas concentration measured at $200^{\circ} \mathrm{C}$ operating temperature.

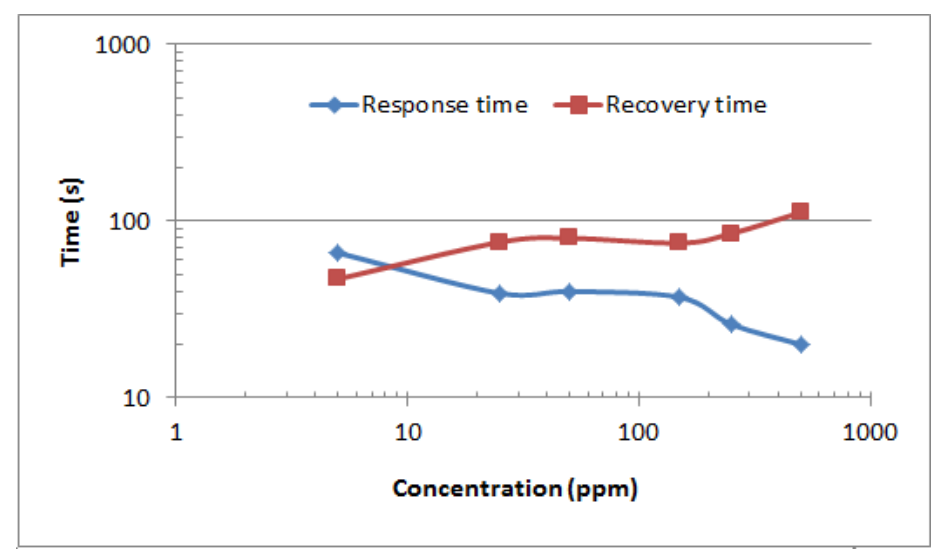

Fig. 18. Dependence of response and recovery times of $\mathrm{MWCNTs} / \mathrm{SnO}_{2} \mathrm{DMF}$ vapor sensor on gas concentration measured at $200^{\circ} \mathrm{C}$ operating temperature.

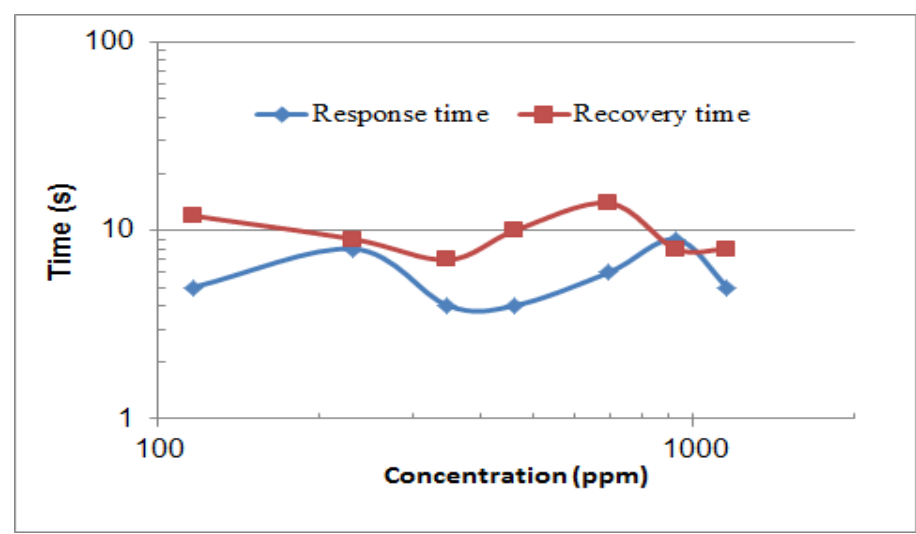

Fig. 19. Dependence of response and recovery times of $\mathrm{MWCNTs} / \mathrm{SnO}_{2} \mathrm{FA}$ vapor sensor on gas concentration measured at $200^{\circ} \mathrm{C}$ operating temperature. 


\section{Possible mechanisms of gas sensitivity}

Earlier, it was shown that $\mathrm{COOH}$ groups, attached on the surface of MWCNTs, have strong interactions with alcohol vapors, which result due to the formation of hydrogen bonds between $\mathrm{COOH}$ groups and $\mathrm{OH}$ groups of alcohol molecules [31, 47]. This hydrogen bond should be removed by increasing the temperature, which contributes to long recovery times in MWCNTs $/ \mathrm{SnO}_{2}$ sensors. The higher operating temperature of the gas response is observed up to the temperature at which the response achieves to its maximal value. With the subsequent increase in operating temperature, desorption of chemisorbed oxygen ions takes place, and the gas response decreases. The recovery times are decreasing. When there is relatively more content of $\mathrm{SnO}_{2}$ in a nanocomposite, as in our case, MWCNTs nanochannels play a smaller role since nanotubes are entirely closed by plenty of $\mathrm{SnO}_{2}$ nanoparticles. Accessibility of gas-molecule penetration to MWCNT nanochannels through the metal-oxide thick film is very difficult. Therefore the response is mainly determined by the number of metal-oxide nanoparticles and a considerable amount of surface adsorption sites. MWCNTs only prevent the formation of $\mathrm{SnO}_{2}$ agglomerates and thereby ensure the developed surface, due to repulsive forces between the carboxyl groups adsorbed on it.

The chemisorption reactions take place on the surface of $\mathrm{SnO}_{2}$ nanocrystallites (with or without $R u$ covering the nanotubes) at the present of methanol, ethanol and i-butane vapors in air have been described in detail earlier [31]. Here, we show only equations of the reactions concerning to ethanol and methanol vapors.

$$
\begin{aligned}
& \mathrm{CH}_{3} \mathrm{OH}+3 \mathrm{O}^{-} \rightarrow \mathrm{CO}_{2}(g)+2 \mathrm{H}_{2} \mathrm{O}(\mathrm{g})+3 e^{-} \\
& \mathrm{C}_{5} \mathrm{H}_{5} \mathrm{OH}+6 \mathrm{O}^{-} \rightarrow 2 \mathrm{CO}_{2}(g)+3 \mathrm{H}_{2} \mathrm{O}(g)+6 e^{-}
\end{aligned}
$$

By analogy with the above equations, the oxidation reaction of PG and DMF vapors on the nanocomposite surface could be represented as follows, respectively:

$$
\begin{gathered}
\mathrm{C}_{3} \mathrm{H}_{8} \mathrm{O}_{2}(g)+8 \mathrm{O}^{-} \rightarrow 3 \mathrm{CO}_{2}(g)+4 \mathrm{H}_{2} \mathrm{O}(\mathrm{g})+8 e^{-} \\
4 \mathrm{C}_{3} \mathrm{H}_{7} \mathrm{NO}(\mathrm{g})+42 \mathrm{O}^{-} \rightarrow 12 \mathrm{CO}_{2}(g)+4 \mathrm{NO}_{2}(g)+14 \mathrm{H}_{2} \mathrm{O}(g)+42 e^{-}
\end{gathered}
$$

At the temperature corresponding to the highest response, the reactivity of the target gas molecules is proportional to the speed of diffusion into the sensing layer. Hence, the target gas has the chance to penetrate sufficiently into the sensing layer and react with an appropriate speed. The competition between the amount of adsorbed target gases and their oxidation rate supports the maximum response and its sharp decline. With the resulting increase in operating temperature, desorption of the adsorbed oxygen ions from the surface of the sensor is growing. It follows that at higher operating temperatures, fewer oxygen ions are present on the surface of 
$\mathrm{SnO}_{2}$, which might be taking part in reaction to target gases. Therefore the response falls at high operating temperatures. Moreover, the temperature has an impact on the physical properties of the semiconducting sensor material. To demonstrate, at higher temperatures the carrier concentration increases (owing to releasing electrons back to the conduction band in consequence of desorption of adsorbed oxygen) and the Debye length decreases. This, in turn, may be one of the possible reasons for the rise in $R_{g}$ curve in Fig. 12, which leads to the decrease in response at higher temperatures.

Although the molecular weight of considered PG and DMF target gases are close to each other, the quantity of carbon atoms is just the same. Response from DMF-vapor exposure is smaller because the adsorbed oxygen ions demand the full oxidation reaction. Therefore a chemical decomposition occurs. Nevertheless, the 1:200 weight ratios of the nanocomposite sensor components, with the relatively large amount of $\mathrm{SnO}_{2}$ particles, promote an initiation of the sufficiently large quantity of ionized adsorption centers which, in turn, ensures a relatively high response to DMF gas exposure.

At exposure to low concentrations of both PG and DMF gases, recovery times become shorter than response times (Figs. 17, 18). We explain this phenomenon by the fact that the chemisorption process is developing slower and on a larger scale than desorption of products, obtained in the course of the chemical reaction. That is due to the necessity of having many adsorption centers for implementation of the oxidation reaction, as well as because of desorption after the exposure by low concentrations of gases, which takes place from the relatively shallow depth of the near-surface layer. Moreover, the loose structure of the sensitive thick film is obtained because of the presence of carbon nanotubes in the nanocomposite facilitates and outlet gaseous products formed by the reaction that leads to a decrease in recovery times.

At the high-impact gas concentrations, after filling adjacent to the surface adsorption sites the remaining target gas molecules, only after overcoming of $\mathrm{SnO}_{2}$ clusters by diffusion and penetrating more rooted in the nanocomposite layer, are adsorbed there. This leads to an increase in response time. The same factors affect the rise in recovery time too.

As Fig. 17 shows, the response and recovery times are highly dependent on the concentration of propylene glycol. Why response and recovery times rise with increase in concentrations of propylene glycol?

As we pointed out above, propylene glycol in the gas phase is obtained by vaporization of the liquid, dripping it on the heated metal plate or by using the temperature resistor (coil). The matter is that, a large amount of the liquid will be vaporized if heat transfer will occur very quickly. At the slow heating, portion of PG vapors loses condenses or absorbs on the chamber walls or in other places. Very quick heating is necessary else in other to have a small amount of heat in a confined space of the measurement chamber and, above all, for ensuring of possibility of the sensor faithful performance determination. Moreover, very high temperature heat source provides a lot of oxygen compared with liquid state [50]. This promotes that at least part of the liquid by heating can attain ignition temperature (flash temperature is only just $64^{\circ} C$ ) instead of plain vaporization. When combustion is complete and there is plenty of oxygen pieces, as an in this case, the chemisorption reaction happens according to equation (3) with formation just volatile $\mathrm{CO}_{2}$ and water to release the conduction electrons. If the combustion is incomplete and 
there is not enough oxygen, intermediate formaldehyde is formed along with the most thermodynamically stable $\mathrm{CO}_{2}$ and water [51]. The oxidation of PG to formaldehyde $\left(\mathrm{CH}_{2} \mathrm{O}\right)$ happens as:

$$
\mathrm{CH}_{2} \mathrm{OH}-\mathrm{CHOH}-\mathrm{CH}_{3}+4 \mathrm{O}^{-} \rightarrow 2 \mathrm{CH}_{2} \mathrm{O}+2 \mathrm{H}_{2} \mathrm{O}+\mathrm{CO}_{2}+4 e^{-}
$$

In this case, we explain the sharp rise in PG response and recovery times at high PG vapor concentrations (beginning from about 300 ppm and higher) by intermediate formaldehyde formation. It is known that formaldehyde molecules are more stable than PG, but less stable than carbon dioxide [52]. So, decomposition of formaldehyde at high temperatures but below $300^{\circ} \mathrm{C}$ occurs very slowly (rate of decomposition is about $0.44 \%$ per minute). The main products of the decomposition are carbon monoxide and hydrogen. We suppose that at least part of the formaldehyde gas molecules is adsorbed on the $R u$ catalyst. Based on the data of works [52-54] where decomposition of formaldehyde on $P t, P d$ and $R u$ has been studied, we can assume that the catalytic decomposition of formaldehyde in our case on ruthenium also occurs as follows:

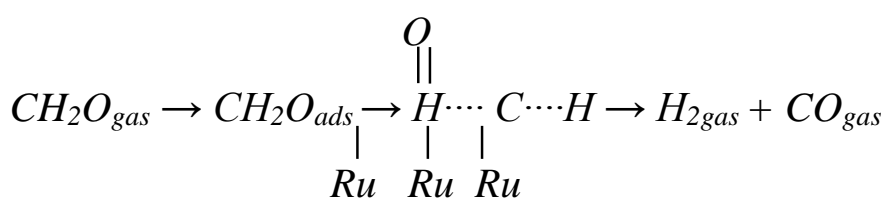

Here, the dotted lines indicate the weak attraction. Oppositely charged adsorbed molecules of hydrogen and carbon monoxide are reacted in the adsorption layer. The primary product of this interaction can be adsorption complex of formaldehyde. The formation of such complexes occurs at low speed and goes with a decrease in the work function [55]. In the presence of carbon monoxide and carbon dioxide gases under hydrogenation simultaneously, these gases are competing for active adsorption centers. Since the carbon monoxide molecules will interact with active sites faster, the hydrogenation of $\mathrm{CO}$ occurs, but not as carbon dioxide [55]. According [52] the process for carbon dioxide, in this case, occurs sufficiently slowly. The time of formaldehyde decomposition at high concentrations of PG is close based on the order of magnitude to the response and recovery times demonstrated in the Figures. At that, more concentrations of PG and more parts of formaldehyde are involved in Eq. (5) as more extended response and recovery times of the sensor. The dominant contribution of the adsorption of formaldehyde or incomplete combustion with an increase in PG concentration is started, apparently, with about $300 \mathrm{ppm}$. Following [52], the presence of $C O$ and its attractive interaction with $\mathrm{H}_{2}$ causes a lowering of hydrogen adsorption energy and an increase in $\mathrm{H}_{2}$ desorption energy, respectively. At lower concentrations of PG, the proportion of adsorbed complex of formaldehyde is negligible, and both response and recovery times are relatively short and defined by the speed of chemisorption and desorption of the Eq. (3) products. As mentioned, the amount of response and recovery times differs based on DMF vapor concentrations (Fig. 11). Smaller gas concentrations require less recovery time than the response time. Practically, in the whole studied concentrations range, with the rise of gas concentration, the response time is decreasing whereas recovery time is increasing. 
Some basic parameters of nanostructured MWCNTs $/ \mathrm{SnO}_{2}$ nanocomposite toxic VOCs sensors researched and developed in YSU are collected in the following Table 3. Optimal operating modes for each sensor are selected taking into account both the high response of the sensors to the target gases, and selectivity, possibly low operating temperature (or power consumption), quick action at the given operating temperature, etc.

Table 3. Basic parameters of researched and developed in YSU nanostructured $\mathrm{MWCNTs} / \mathrm{SnO}_{2}$ nanocomposite toxic VOCs sensors.

\begin{tabular}{|c|c|c|c|c|c|c|}
\hline Gas (vapor) & $\begin{array}{c}\text { Gas } \\
\text { response, } \\
\mathbf{R}_{\mathbf{a}} / \mathbf{R}_{\mathbf{s}}\end{array}$ & $\begin{array}{c}\mathbf{G a s} \\
\text { concentration, } \\
\mathbf{p p m}\end{array}$ & $\begin{array}{c}\text { Operating } \\
\text { temperature, } \\
{ }^{\mathbf{C}}\end{array}$ & $\begin{array}{c}\text { Respon } \\
\text { se time, } \\
\mathbf{s}\end{array}$ & $\begin{array}{c}\text { Recover } \\
\mathbf{y} \text { time, } \mathbf{s}\end{array}$ & References \\
\hline Methanol & 2000 & 1000 & 200 & 60 & 100 & {$[30],[31]$} \\
\hline Toluene & 350 & 1000 & 150 & 24 & 14 & [56], [57], hear \\
\hline DMF & 42.04 & $500\left(5^{*}\right)$ & 225 & 5 & 50 & [58], [59], hear \\
\hline PG & 125 & $650(13.5)$ & 200 & 7 & 600 & [58], [59], hear \\
\hline Formaldehyde & 5 & $1160(115)$ & 225 & 4 & 11 & [59], [60], hear \\
\hline Butanol & 1269.3 & 1000 & 165 & 12 & 40 & {$[48]$} \\
\hline i-butane & 100 & $5000(45)$ & 250 & $1-2$ & 10 & {$[31]$} \\
\hline Acetone & 555.6 & $1000(<1)$ & 250 & 22 & 27 & {$[56]$, (in press) } \\
\hline Ammonia & 695.8 & 1000 & 200 & 16 & 27 & [61] \\
\hline
\end{tabular}

* The minimal gas concentrations in ppm units at which the perceptible signal was registered is shown inside the brackets

** $\mathrm{MWCNTs} / \mathrm{SnO}_{2}$ nanocomposite structures presented in this table differ from each other by the ratio of the nanocomposite components as well as by the various used processing technologies

\section{Conclusion}

Thus, in this work are found definite conditions at which of studied MWCNTs $/ \mathrm{SnO}_{2}$ nanocomposite gas sensor exhibit the selective reaction to acetone and toluene vapors. This one are achieved both by selection of samples with corresponding mass ratio of the nanocomposite components and optimal operating temperature So, it is revealed that the nanocomposite structures with 1:4 mass ratio of the components selectively respond to acetone vapors at $150^{\circ} \mathrm{C}$ and acetone and toluene vapors at $250^{\circ} \mathrm{C}$ operating temperatures. Nanocomposite samples with greater mass ratio of the components $(1: 8,1: 24,1: 50,1: 66$ and $1: 200)$ behave as a very sensitive and selective ethanol and methanol sensors at $200^{\circ} \mathrm{C}$ operating temperature [30,31]. We can assert that in this range of mass ratio of the nanocomposite components, the sensors made by using the mentioned above hydrothermal synthesis, sol-gel technique and their combined process technologies react to these alcohols something like, e.g. alcohols responses practically not depend from used processing methods. Acetone vapors selective sensitivity of samples with 1:50 mass ratio of the components appears only at $300^{\circ} \mathrm{C}$ operating temperature. 
The largest and sufficiently selective response to acetone vapors $\left(R_{a} / R_{g}\right.$ more than 1000 at $1000 \mathrm{ppm}$ acetone vapor concentration) is achieved for samples with 1:200 mass ratio of the components.

We have investigated also ruthenated MWCNTs $/ \mathrm{SnO}_{2}$ thick-film nanocomposite sensors using hydrothermal synthesis and sol-gel technologies. It is revealed that sensors give a sufficiently high response to such harmful and hazardous gases as PG, DMF and FA at relatively low operating temperatures. The fast response of the sensors (on the order of seconds) and acceptable recovery times are observed under all gas concentrations influence at $200^{\circ} C$ operating temperature. The minimal PG, DMF and FA gas concentrations at which the perceptible signal is registered are 13,5 and $115 \mathrm{ppm}$, respectively. Due to the linear dependence of the response on the concentration of PG, DMF and FA vapors, it is possible to measure the concentration of mentioned gases in the atmosphere quickly.

An interpretation of the results obtained is given, including the mechanisms of sensitivity to the gases under consideration, response/recovery and temperature characteristics.

Thus, by means of certain choice of the gas sensor processing technique, weight ratio of the nanocomposite components and the best operating temperature, as well as by impregnating the sensor structures with Ru catalyst, it is possible adjusting the surface-ruthenated MWCNT $/ \mathrm{SnO}_{2}$ nanocomposite based gas sensors sensitivity and response recovery times as well as selectivity to considered harmful and toxic VOS.

\section{References}

[1] S. Gokhale, T. Kohajda, U. Schlink, Source apportionment of human personal exposure to volatile organic compounds in homes, offices and outdoors by chemical mass balance and genetic algorithm receptor models, Sci. Total Environ. 407 (2008) 122-138.

[2] S. Wang, H.M. Ang, M.O. Tade, Volatile organic compounds in indoor environment and photocatalytic oxidation: state of the art, Environ. Int. 33 (2007) 694-705.

[3] K. Inyawilert, A. Wisitsoraat, A. Tuantranont, P. Singjai, S. Phanichphant, C. Liewhiran, Ultra-rapid VOCs sensors based on sparked- $\mathrm{In}_{2} \mathrm{O}_{3}$ sensing films, Sensors and Actuators B 192 (2014) 745- 754.

[4] S.A. Feyzabad, A.A. Khodadadi, M.V. Naseh, Y. Mortazavi, Highly sensitive and selective sensors to volatile organic compounds using MWCNTs/SnO 2 , Sens. Actuators B 166-167 (2012) 150-155.

[5] X. Li, Y. Chang, Y. Long, Influence of Sn doping on $\mathrm{ZnO}$ sensing properties for ethanol and acetone, Mater. Sci. Eng. C 32 (2012) 817-821.

[6] C. Garzella, E. Comini, E. Bontempi, L.E. Depero, C. Frigeri, G. Sberveglieri, Sol-gel $\mathrm{TiO}_{2}$ and W/TiO 2 nanostructured thin films for control of drunken driving, Sens. Actuators B 83 (2002) 230-237.

[7] T. Brousse, D.M. Schleich, Sprayed and thermally evaporated $\mathrm{SnO}_{2}$ thin films for ethanol sensors, Sens. Actuators B 31 (1996) 77-79.

[8] M. Salaspuro, Acetaldehyde as a common denominator and cumulative carcinogen in digestive tract cancers, Scandinavian J. of Gastroenterology, 44 (8) (2009) 912-925.

[9] Xue Bai, Huiming Ji, Peng Gao, Ying Zhang, Xiaohong Sun, Morphology, phase structure and acetone sensitive properties of copper-doped tungsten oxide sensors, Sens. Actuators B 193 (2014) 100-106.

[10] N. Makisimovich, V. Vorotyntsev, N. Nikitina, O. Kaskevich, P. Karabun, F. Martynenko, Adsorption semiconductor sensor for diabetic ketoacidosis diagnosis,Sens. Actuators B 35-36 (1996) 419-421.

[11] L. Wang, A. Teleki, S.E. Pratsinis, P.I. Gouma, Ferroelectric $\mathrm{WO}_{3}$ nanoparticles for acetone selective detection, Chem. Mater. 20 (2008) 4794-4796.

[12] J. Lerchner, D. Caspary, G. Wolf, Calorimetric detection of volatile organic compounds, Sens. Actuators B: Chem. 70 (2000) 57-66. 
[13] M. Consales, A. Crescitelli, M. Penza, P. Aversa, P.D. Veneri, M. Giordano, A. Cusano, SWCNT nanocomposite optical sensors for VOC and gas trace detection, Sens. Actuators B: Chem. 138 (2009) 351-361.

[14] T. Sasahara, H. Kato, A. Saito, M. Nishimura, M. Egashira, Development of a ppb level sensor based on catalytic combustion for total volatile organic compounds in indoor air, Sens. Actuators B: Chem. 126 (2007) 536-543.

[15] M. Hanada, H. Koda, K. Onaga, K. Tanaka, T. Okabayashi, T. Itoh, H. Miyazaki, Portable oral malodor analyzer using highly sensitive $\mathrm{In}_{2} \mathrm{O}_{3}$ gas sensor combined with a simple gas chromatography system, Anal. Chim. Acta 475 (2003) 27-35.

[16] C. Xu, J. Tamaki, N. Miura, N. Yamazoe, Grain size effects on gas sensitivity of porous $\mathrm{SnO}_{2}$-based elements, Sensors and Actuators B 3 (1991) 147-155.

[17] G. Korotcenkov, S.-D. Han, B.K. Cho, V. Brinzari, Grain size effects in sensor response of nanostructured $\mathrm{SnO}_{2}$ - and $\mathrm{In}_{2} \mathrm{O}_{3}$-based conductometric thin film gas sensor, Critical Reviews in Solid State and Materials Sciences 34 (2009) 1-17.

[18] A.Z. Adamyan, Z.N. Adamyan, V.M. Aroutiounian, A.H. Arakelyan, J. Turner, K. Touryan, Sol-gel derived thin-film semiconductor hydrogen gas sensor, International Journal of Hydrogen Energy 32 (2007) 4101-4108.

[19] M. Tonezzer, N.V. Hieu, Size-dependent response of single-nanowire gas sensors, Sensors and Actuators B 163 (2012) 146-152.

[20] Wang, L.F. Zhu, Y.H. Yang, N.S. Xu, G.W. Yang, Fabrication of a $\mathrm{SnO}_{2}$ nanowire gas sensor and sensor performance for hydrogen, Journal of Physical Chemistry C 112 (2008) 6643-6647.

[21] L.P. Qin, J.Q. Xu, X.W. Dong, Q.Y. Pan, Z.X. Chen, Q. Xiang, F. Li, The template free synthesis of squareshaped $\mathrm{SnO}_{2}$ nanowires: the temperature effect and acetone gas sensors, Nanotechnology 19 (2008) 185705.

[22] X.M. Han, B. Zhang, S.K. Guan, J.D. Liu, X. Zhang, R.F. Chen, Gas-sensing properties of $\mathrm{SnO}_{2}$ nanobelts synthesized by thermal evaporation of Sn foil, Journal of Alloys and Compounds 461 (2008) L26-L28.

[23] Youngjae Kwon, Hyunsu Kim, Sangmin Lee, In-Joo Chin, Tae-Yeon Seong, Wan In Lee, Chongmu Lee, Enhanced ethanol sensing properties of $\mathrm{TiO}_{2}$ nanotube sensors, Sensors and Actuators B 173 (2012) 441- 446.

[24] Yi-Jing Li, Kun-Mu Li, Chiu-Yen Wang, Chung-I. Kuo, Lih-Juann Chen, Low-temperature electrodeposited Co-doped $\mathrm{ZnO}$ nanorods with enhanced ethanol and CO sensing properties, Sensors and Actuators B 161 (2012) 734-739.

[25] Y. Tan, C.C. Li, Y. Wang, J.F. Tang, X.C. Ouyang, Fast-response and high sensitivity gas sensors based on $\mathrm{SnO}_{2}$ hollow spheres, Thin Solid Films 516 (2008) 7840-7843.

[26] L. Cheng, S.Y. Ma, X.B. Li, J. Luo, W.Q. Li, F.M. Li, Y.Z. Mao, T.T. Wang, Y.F. Li, Highly sensitive acetone sensors based on $\mathrm{Y}$-doped $\mathrm{SnO}_{2}$ prismatic hollow nanofibers synthesized by electrospinning, Sensors and Actuators B 200 (2014) 181-190.

[27] Lin Mei, Jiwei Deng, Xiaoming Yin, Ming Zhang, Qiuhong Li, Endi Zhang, Zhi Xu, Libao Chen, Taihong Wang, Ultrasensitive ethanol sensor based on 3D aloe-like $\mathrm{SnO}_{2}$, Sensors and Actuators B 166-167 (2012) 7-11.

[28] L. Zhao, M. Choi, H.-S. Kim, S.-H. Hong, The effect of multiwalled carbon nanotube doping on the CO gas sensitivity of $\mathrm{SnO}_{2}$-based nanomaterials, Nanotechnology, 18 (2007) 445501.

[29] Sadegh Ahmadnia-Feyzabad, Abbas Ali Khodadadia, Masoud Vesali-Naseh, Yadollah Mortazavi, Highly sensitive and selective sensors to volatile organic compounds using $\mathrm{MWCNTs} / \mathrm{SnO}_{2}$, Sensors and Actuators B 166-167 (2012) 150-155.

[30] V.M. Aroutiounian, A.Z. Adamyan, E.A. Khachaturyan, Z.N. Adamyan, K. Hernadi, Z. Pallai, Z. Nemeth, L.

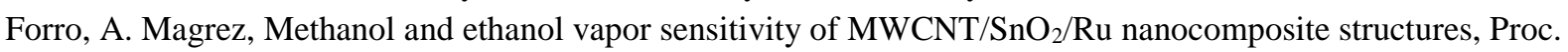
of the $14^{\text {th }}$ Int. Meeting on Chemical sensors (IMCS 2012), May 20-23, 2012, Nuremberg, Germany, pp. 10851088.

[31] V.M. Aroutiounian, A.Z. Adamyan, E.A. Khachaturyan, Z.N. Adamyan, K. Hernadi, Z. Pallai, Z. Nemeth, L. Forro, A. Magrez, E. Horvath, Study of the surface-ruthenated $\mathrm{SnO}_{2} / \mathrm{MWCNTs}$ nanocomposite thick-film gas sensors, Sensors and Actuators B 177 (2013) 308-315.

[32] P. Berki, Z. Németh, B. Réti, O. Berkesi, A. Magrez, V. Aroutiounian, L. Forró, K. Hernadi, Preparation and characterization of multiwalled carbon nanotube/ $\mathrm{In}_{2} \mathrm{O}_{3}$ composites, Carbon 60 (2013) 266-272.

[33] N.V. Hieu, L.T.B. Thuy, N.D. Chien, Highly sensitive thin film $\mathrm{NH}_{3}$ gas sensor operating at room temperature based on $\mathrm{SnO}_{2}$ /MWCNTs composite, Sensors and Actuators B 129 (2008) 888-895. 
[34] Y.-L. Liu, H.-F. Yang, Y. Yang, Z.-M. Liu, G.-L. Shen, R.-Q. Yu, Gas sensing properties of tin dioxide coated carbon nanotubes, Thin Solid Films 497 (2006) 355-360.

[35] B.-Y. Wei, M.-C. Hsu, P.-G. Su, H.-M. Lin, R.-J. Wu, H.-J. Lai, A novel $\mathrm{SnO}_{2}$ gas sensor doped with carbon nanotubes operating at room temperature, Sensors and Actuators B 101 (2004) 81-89.

[36] G. Korotcenkov, S.H. Han, B.K. Cho, Material design for metal oxide chemiresistive gas sensors, Journal of Sensor Science and Technology 22(1) (2013) 1-17.

[37] A. Fiorito, F. Larese, S. Molinari, and T. Zanin, Liver function alterations in synthetic leather workers exposed to dimethylformamide, Am. J. Ind. Med., 32, 255-260, https://doi.org/10.1002/(SICI)10970274(199709)32:3<255::AID-AJIM11>3.0.CO;2-U, 1997.

[38] M. A Lefebvre, W. J. Meulingb, R.Engel, M.C. Coroamac, G. Rennerc, W. Pape, and G.J. Nohynek, Consumer inhalation exposure to formaldehyde from the use of personal care products/cosmetics, Regul. Toxicol. Pharm., 63, 171-176, https://doi.org/10.1016/j.yrtph.2012.02.011, 2012.

[39] G. Malaguarnera, E. Cataudella, M. Giordano, G. Nunnari, G. Chisari, and M. Malaguarnera, Toxic hepatitis in occupational exposure to solvents, World. J. Gastroentero., 18, 2756-2766. https://doi.org/10.3748/wjg.v18.i22.2756, 2012.

[40] H.Y. Chang, T.S. Shih, Y.L.Guo, C.Y. Tsai, and P.C. Hsu, Sperm function in workers exposed to N,Ndimethylformamide in the synthetic leather industry, Fertil. Steril., 81, 1589-1594, https://doi.org/10.1016/j.fertnstert.2003.10.033, 2004.

[41] Robertson, O. H., Loosli, C. G., and Puck, T. T.: Test for chronic toxicity of propylene glycol and triethylene glycol on monkeys and rats by vapor inhalation and oral administration, J. Pharmacol. Exp. Ther., 91, 52-76, 1947.

[42] T. Salthammer, S. Mentese, and R. Marutzky, Formaldehyde in the indoor environment, Chem. Rev., 110, 2536-2572, https://doi.org/10.1021/cr800399g, 2010.

[43] M. J. Ellenhorn, S. Schonwald, G. Ordog, and J. Wasserberger, Ellenhorn's medical toxicology: diagnosis and treatment of human poisoning, 2nd edition, MD: Williams \& Wilkins, Baltimore, USA, 1675, 1997.

[44] 37. E. Couteau, K. Hernadi, J.W. Seo, L. Thien-Nga, Cs. Mikó, R. Gáal, L. Forró, CVD synthesis of highpurity multiwalled carbon nanotubes using $\mathrm{CaCO}_{3}$ catalyst support for large-scale production, Chem. Phys. Lett., 378, 9-17, 2003.

[45] Arnaud Magrez, Jin Won Seo, Rita Smajda, Marijana Mionić, László Forró, Catalytic CVD Synthesis of Carbon Nanotubes: Towards High Yield and Low Temperature Growth, Materials 3 4871-4891, 2010.

[46] Zoltan Nemeth, Balazs Reti, Zoltan Pallai,Peter Berki, Judit Major, Endre Horvath, Arnaud Magrez, Laszlo Forro, Klara Hernadi, Chemical challenges during the synthesis of MWCNT-based inorganic nanocomposite materials, Phys. Status Solidi B, 1-6, 2014.

[47] Thanh Thuy Trinh, Ngoc Han Tu, Huy Hoang Le, Kyung Yul Ryu, Khac Binh Le, Krishnakumar Pillai, Junsin $\mathrm{Yi}$, Improving the ethanol sensing of $\mathrm{ZnO}$ nano-particle thin films-The correlation between the grain size and the sensing mechanism," Sensors and Actuators B 152, 73-81, 2011.

[48] Z.N. Adamyan, A.G Sayunts, E. A, Khachaturyan, and V.M. Aroutiounian, Study of nanocomposite thick-film butanol vapor sensors, J. Contemp. Phys., 51, 143-149,

https://doi.org/10.3103/S1068337216020067, 2016.

[49] M.L.Y. Sin, G.C.T. Chow, G.M.K. Wong, W.J. Li, P.H.W. Leong, K.W. Wong, Ultralow-power alcohol vapor sensors using chemically functionalized multiwalled carbon nanotubes, IEEE Transactions on Nanotechnology 6 (5) (2007) 571-577.

[50] Jr., J.R. Walter, G. McClure, P.W. Brown, and K.G. Galuk, An investigation of the degradation of aqueous ethylene glycol and propylene glycol solutions using ion chromatography, Sol. Energ. Mater., 11, 455-467, https://doi.org/10.1016/0165-1633(85)90016-4, 1985.

[51] R.P. Jensen, W. Luo, J.F. Pankow, R.M. Strongin, and D.H Peyton, Hidden Formaldehyde in E-Cigarette Aerosols, New Engl. J. Med., 372, 392-394, 2015.

https://doi.org/10.1056/NEJMc1413069,2015

[52] G. Ertl and J. Tornau, The catalytic decomposition of formaldehyde on palladium, Z. Phys. Chem. Neue. Fol., 104, 301-308, 1977. 
[53] M.A. Vannice, The catalytic synthesis of hydrocarbons from $\mathrm{H}_{2} \mathrm{CO}$ mixtures over the group VIII metals: II. The kinetics of the methanation reaction over supported metals, J. Catal., 37, 462-473, 1975. https://doi.org/10.1016/0021-9517(75)90182-7, 1975.

[54] T. Borowiecki, and J. Barcicki, Selectivity of the steam reforming of methane over metallic catalysts, React. Kinet. Catal. L., 12, 101-106, 1979. https://doi.org/10.1007/BF02071432, 1979.

[55] V.M. Vlasenko, and G.E. Yuzefovich, Mechanism of the Catalytic Hydrogenation of Oxides of Carbon to Methane, Russ. Chem. Rev., 38, 728-739, DOI: 10.1070/RC1969v038n09ABEH001829, 1969.

[56] Vladimir M. Aroutiounian, Zaven N. Adamyan, Artak G. Sayunts, Emma A. Khachaturyan, Arsen Z. Adamyan, Study of MWCNT/SnO ${ }_{2}$ Nanocomposite Acetone and Toluene Vapor Sensors, Proc, of 17 Int. Conference on Sensors and Measurement Technology, SENSOR 2015, May 19-21, Nuremberg, Germany, 836841, 2015. DOI 10.5162/sensor2015/P8.3

[57] Vladimir Aroutiounian, Zaven Adamyan, Artak Sayunts, Emma Khachaturyan, Arsen Adamyan, Klara Hernadi, Zoltan Nemeth, Peter Berki, Comparative Study of VOC Sensors Based on Ruthenated MWCNT/SnO Nanocomposites, Int.J. of Emerging Trends in Science and Technology (IJETST), 01/08, pp. 1309-1319, 2014. ISSN 2348-9480

[58] Zaven Adamyan, Artak Sayunts, Vladimir Aroutiounian, Emma Khachaturyan, Arsen Adamyan, Martin Vrnata, Přemysl Fitl, Jan Vlček, Study of Propylene Glycol and Dimethylformamide Vapors Sensors Based on MWCNTs/ $\mathrm{SnO}_{2}$ Nanocomposites, Proc. of The Second International Conference on Advances in Sensors, Actuators, Metering and Sensing (ALLSENSORS 2017), Nice, France, Mart 19-23, 2017 pp. 44-49.

[59] Z. Adamyan, A. Sayunts, V. Aroutiounian, E. Khachaturyan, A. Adamyan, M. Vrnata, P. Fitl, J. Vlček, MWCNTs $/ \mathrm{SnO}_{2}$ Harmful Gas Sensors, Proc. of the 18th International Conference on Sensors and Measurement Technology (AMA Conferences 2017) Nuremberg, Germany, May 30 - June 1, 2017, pp. 708-713. DOI 10.5162/sensor2017/P5.5

[60] Zaven Adamyan, Artak Sayunts, Vladimir Aroutiounian, Emma Khachaturyan, Martin Vrnata, Přemysl Fitl, and Jan Vlček, Nanocomposite sensors of propylene glycol, dimethylformamide and formaldehyde vapors, J. of Sensors \& Sensor Systems, 7, 31-41, 2018; https://doi.org/10.5194/jsss-7-31-2018

[61] A.G. Sayunts, On selectivity of surface-ruthenated $\mathrm{MWCNT} / \mathrm{SnO}_{2}$ nanocomposite VOCs sensors, Proc. of 10 Int. Conference on Semiconductor Micro- and Nanoelectronics, 2015, September 11-13, Yerevan, Armenia, pp. 78-81. 